\title{
Çocukluk çağı Ewing Sarkomlu olguların retrospektif değerlendirilmesi
}

\section{Retrospective assessment of patients with pediatric Ewing's sarcoma}

\author{
Beyhan Bülbül $* a^{*}$, Murat Elli ${ }^{a}$, Ayhan Dağdemir ${ }^{a}$, Nevzat Dabak $^{b}$, Sabri Acar $^{a}$, Sancar Barış $^{c}$, Mustafa Bekir Selçuk $^{d}$, \\ Gönül Oğure
}

a Ondokuz Mayıs Üniversitesi, Tıp Fakültesi Çocuk Hematolojisi ve Onkolojisi Anabilim Dalı, Samsun

b Ondokuz Mayıs Üniversitesi, Tip Fakültesi Ortopedi ve Travmatoloji Anabilim Dalı, Samsun

c Ondokuz Mayıs Üniversitesi, Tıp Fakültesi Patoloji Anabilim Dalı, Samsun

d Ondokuz Mayıs Üniversitesi, Tıp Fakültesi Radyasyon Onkolojisi Anabilim Dalı, Samsun

e Ondokuz Mayıs Üniversitesi, Tıp Fakültesi Pediatri Genetik Anabilim Dalı, Samsun

\begin{tabular}{|c|c|}
\hline МАК & GÍLERİ \\
\hline Mak & \\
\hline Geliş & $02 / 08 / 2010$ \\
\hline Kabul & $19 / 08 / 2010$ \\
\hline
\end{tabular}

\section{* Yazışma Adresi:}

Beyhan Bülbül

Ondokuz Mayıs Üniversitesi Tıp Fakültesi,

Çocuk Hematolojisi ve Onkolojisi BD

Kurupelit, Samsun

e-posta: drbeyhanbulbul@hotmail.com

\section{Anahtar Kelimeler:}

Ewing Sarkom

Çocukluk Çağı

Retrospektif

Analiz

Tedavi

Sonuçlar

\section{Keywords:}

Ewing's Sarcoma

Childhood

Retrospective

Analyze

Treatment

Outcome

\section{ÖZET}

Bu çalışmada Çocuk Hematoloji-Onkoloji Bilim Dalı'nda takip ve tedavi edilen 27 Ewing Sarkomlu olgunun epidemiyolojik ve klinik özellikleri, tedavi sonuçları, uzun dönem komplikasyonları retrospektif olarak incelenmiştir. Olguların $(n=27)$ ortalama tanı yaşı $11,36 \pm 3,98$ yıl ( 8 ay- 17,9$)$ olup, erkek/kız oranı 1,7 olarak saptandı. En sık başvuru yakınmalarının lokalize ağrı $(\% 96,3)$ ve şişlik $(\% 100)$ olduğu görüldü. Primer tümör bölgesi 16 olguda $(\% 59,3)$ uzun kemiklerde, 11 olguda $(\% 40,7)$ aksiyel kemiklerde saptand. Primer lezyonun yerleştiği kemikler sırasıyla femur $(\% 26)$, tibia $(\% 14,8)$, pelvis $(\% 14,8)$ ve fibula $(\% 11,1)$ idi. Başvuru anında 3 olguda ( \%11,1) kemik iliği tutulumu tespit edildi. Toplam 9 olguda $(\% 33,3)$ tanı sirasinda uzak yayılım saptand1. 23 olguya (\%92) neoadjuvan kemoterapi, 17 olguya $(\% 77,2)$ adjuvan kemoterapi uygulandığ tespit edildi. Olguların 13'üne ekstremite koruyucu cerrahi, 2'sine amputasyon yapıldığı saptandı. Radyoterapi olguların \%65,3'ünde uygulandı $(n=17)$ ve radyoterapi yeri 11 olguda primer tümör bölgesine, 5 olguda metastaz bölgesine, 1 olguda hem primer tümör hem metastaz bölgesine yönelik idi. Olgularının ortalama ve ortanca izlem süreleri sırasıyla 35,5 ve 19 ay (en fazla 355 ay) idi. Sağ kalım analizleri sonucunda toplam sağ kalım oranı $\% 22,4 \pm 10,9$ olarak saptand1.

J. Exp. Clin. Med., 2010; 27: 66-72

\begin{abstract}
In this study, 27 patients with Ewing's sarcoma admitted to Pediatric Hematology and Oncology Department were evaluated retrospectively. The epidemiologic and clinical features, treatment results, long term side effects of therapy of 27 patients with Ewing's sarcoma were analyzed. The mean age of patients with Ewing's sarcoma $(n=27)$ was 11.36 \pm 3.98 years (range, 8 months- 17.9 years) and male/female ratio was 1.7 . The most common complaints were pain $(96.3 \%)$ and swelling $(100 \%)$. A total of $16(59.3 \%)$ primary tumors were located in an extremity, whereas $11(40.7 \%)$ occured in the axial skeleton. The most common primary lesion sites were femur $(26 \%)$, tibia $(14.8 \%)$, pelvis $(14.8 \%)$ and fibula $(11.1 \%)$ respectively. At diagnosis 3 patients $(11.1 \%)$ had bone marrow metastases. A total of 9 patients (33.3\%) had metastases at diagnosis. 23 patients $(92 \%)$ received neoadjuvant chemotherapy and 17 patients received $(77.2 \%)$ adjuvant chemotherapy. Limb salvage surgery was applied in 13 patients and amputation was made in 2 patients. Seventeen patients $(65.3 \%)$ received radiotherapy; to the primary lesion site in 11 patients, the metastatic site in 5 patients, and both sites in one patient. The mean and median follow-up of patients with Ewing's sarcoma was 35.5 and 19 months respectively (maximum 355 months). The overall survival rate was $22.4 \pm 10.9 \%$.
\end{abstract}

J. Exp. Clin. Med., 2010; 27: 66-72

(C) 2010 OMÜ Tüm Hakları Saklıdır.

\section{Giriş}

Ewing Sarkomu (ES), çocukluk çağında osteosar- komdan sonra kemiğin ikinci sıklıkta görülen nöral orijinli, postganglionik parasempatik kolinerjik nöronlardan 
köken alan andiferansiye bir tümörüdür (Jürgens ve ark., 1998; Redner, 2005). Daha diferansiye şekli ise primitif nöroektodermal tümör (PNET) olarak adlandırılır. İlk kez 1921 'de James Ewing tarafından tanımlanmış ve kemiğin diffüz endotelyoması olarak adlandırılmıştır (Ewing, 1921; Khoury, 2005). Y1ll1k insidansı beyaz ırkta milyonda 3; siyah 1rkta oldukça nadirdir. Erkeklerde kızlara oranla daha sık görülmektedir. Olguların \%80'i 20 yaşın altında olup, insidansı 10-15 yaşlarında pik yapar (Fizazi ve ark., 1998; Cotterill ve ark., 2000; Kennedy ve ark., 2003; Bernstein ve ark., 2006). Türk Pediatrik Onkoloji Grubu (TPOG) ve Türk Pediatrik Hematoloji Derneği (TPHD) 2002-2009 yılları arası çocukluk çağı kanser kayıtlarına göre malign kemik tümörleri toplanan 12087 hastanın olduğu seride 692 olgu ile tüm grubun \%5,7'sini oluşturmaktadır ve bunların 325'ini $(\% 46,97)$ Ewing Sarkom oluşturmaktadır (Kutluk ve Yeşilipek, 2010).

Yassı kemikler en sik tutulum bölgesidir. Uzun kemiklerde tipik olarak diafiz bölgesi tutulmaktadır. En sik tutulan yerler sirasıyla pelvik kemikler, alt ekstremitenin uzun kemikleri ve gögüs duvarının kemikleridir. Alt ekstremitede en s1k femur tutulumu görülür. En sık görülen yakınmalar diğer malign kemik tümörlerinde olduğu gibi lokal ağrı (\%96) ve şişliktir (\%61) (Redner, 2005; Bernstein ve ark., 2006).

\section{Gereç ve Yöntem}

Bu çalışmada Ondokuz Mayıs Üniversitesi Çocuk Hematoloji-Onkoloji Bilim Dalı'nda takip ve tedavi edilen 27 Ewing Sarkom olgusu retrospektif olarak değerlendirildi. Veriler Microsoft Excel 2007 programına kaydedildi ve SPSS 15.0 for Windows programında istatiksel analiz edildi. Tanımlayıcı istatistikler yanında sayısal verilerin karşılaştırılmasında parametrik olanlarda Student-t testi, parametrik olmayanlarda Mann-Whitney-U testi kullanıld. Nitelikli verilerin karşılaştırılmasında, ki-kare testi yapıldı. Sağkalım analizi Kaplan-Meier sağkalım analizine göre yapıldı.

\section{Bulgular}

Olguların ( $\mathrm{n}=27$ ) ortalama tanı yaşı 11,36 $\pm 3,98$ (en küçük yaş 8 ay ve en büyük yaş 17,9) saptandı. Dokuz olgu $(\% 33,3) 10$ yaş altında, 18 olgu $(\% 66,7) 10$ yaş ve üstünde idi. Olguların 17'i erkek (\%62,97), 10’u kı (\%37,03) olup, erkek/kız oranı 1,7 olduğu saptandı. 27 olgunun 4'ünün $(\% 14,8) 1994$ y1lından önce, 23'ünün $(\% 85,2) 1994$ y1l ve sonrasında tanı aldığ saptandı. Anamnez bilgilerine göre lokalize ağrı $(\% 96,3)$ ve şişliğin (\%100) en sık karşılaşılan yakınmalar olduğu görüldü. Olguların başvuru semptom ve bulguları Tablo 1'de verilmiştir.

Olguların şikâyetlerin başlangıç süresine bakıldığında; tüm olguların ortalama yakınma süresi $4 \pm 1,03$ aydı. Olguların \%3,7'i $(n=1)$ 0-15 gün, \%29,6’s1 $(n=8) 15$ gün ile 1 ay arasında, $\% 40,7$ 'si (n=11) $1-3$ ay arasında, $\% 14,8^{\prime} i$ $(n=4)$ 3-6 ay arasında, \%11,1'i (n=3) altı aydan uzun sürelerde yakınması olduğu görüldü.
Tablo 1. Olguların başvuru semptom ve bulguları

\begin{tabular}{|l|c|c|}
\hline Semptom ve bulgu & Sayı (n) & Yüzde (\%) \\
\hline Lokalize şişlik & 27 & 100,0 \\
\hline Lokalize ağrı & 26 & 96,3 \\
\hline Hareket kısıtlılığı & 18 & 66,7 \\
\hline Yürüme bozukluğu & 15 & 55,6 \\
\hline Lokalize hassasiyet & 11 & 40,7 \\
\hline Lokalize ısı artışı & 6 & 22,2 \\
\hline Lokalize eritem & 4 & 14,8 \\
\hline Patolojik kırık & 1 & 3,7 \\
\hline Ayaklarda uyuşma & 1 & 3,7 \\
\hline
\end{tabular}

Primer lezyon \%59,3 ( $\mathrm{n}=16)$ uzun kemiklerde, $\% 40,7(n=11)$ aksiyel kemikte saptand. Olguların primer yerleştiği kemiğe göre dağglımı Tablo 2'de verilmiştir. Primer kemikte yerleşimine göre; olguların \%62,5'inde $(n=10)$ sadece diafiz, \%31,3'ünde $(n=5)$ metafizodiafiz, $\% 6,2$ 'sinde $(\mathrm{n}=1)$ sadece metafiz tutulumu saptand1 (Tablo $3)$. Toplamda olguların $\% 37,5$ inde $(n=6)$ metafiz tutulumu tespit edildi.

Tablo 2. Olguların primer yerleştiği kemiğe göre dağılımı

\begin{tabular}{|l|c|c|}
\hline Primer yerleştiği kemik & Sayı (n) & Yüzde (\%) \\
\hline Femur & 7 & 26 \\
\hline Tibia & 4 & 14,8 \\
\hline Pelvis & 4 & 14,8 \\
\hline Fibula & 3 & 11,1 \\
\hline Skapula & 2 & 7,4 \\
\hline Kosta & 2 & 7,4 \\
\hline Humerus & 1 & 3,7 \\
\hline Vertabla & 1 & 3,7 \\
\hline Klavikula & 1 & 3,7 \\
\hline Femur + Tibia & 1 & 3,7 \\
\hline Kranium + Pelvis & 1 & 3,7 \\
\hline
\end{tabular}

Olguların başvuru sırasındaki ortalama tümör volümü erkeklerde 1304,69 \pm 1606 ml, k1zlarda 2331,05 \pm 1962 $\mathrm{ml}$ idi.Tümör volümü bilinen 20 olgunun $\% 90$ 'ında $(\mathrm{n}=18)$ $\geq 100 \mathrm{ml}, \% 10$ 'unda $(\mathrm{n}=2)<100 \mathrm{ml}$ saptandi.

Olguların \% 77,8' inde tanının insizyonel biyopsi ile $(\mathrm{n}=21), \% 14,8^{\prime}$ ine eksizyonel biyopsi $(\mathrm{n}=4), \% 7,4$ 'üne tru-cut biyopsi $(\mathrm{n}=2)$ ile tanı konulduğu saptandı. Patolojik incelemede olguların \% 80'inde $(\mathrm{n}=12)$ immunohistokimyasal olarak CD99 pozitif boyanma olduğu saptandı. Tümör sitogenetik analizi çalışılan 7 olgunun 4'ünde $(\% 57,1)$ $\mathrm{t}(11 ; 22)(\mathrm{q} 24 ; \mathrm{q} 12)$ saptand1. Translokasyon saptanan olgu-

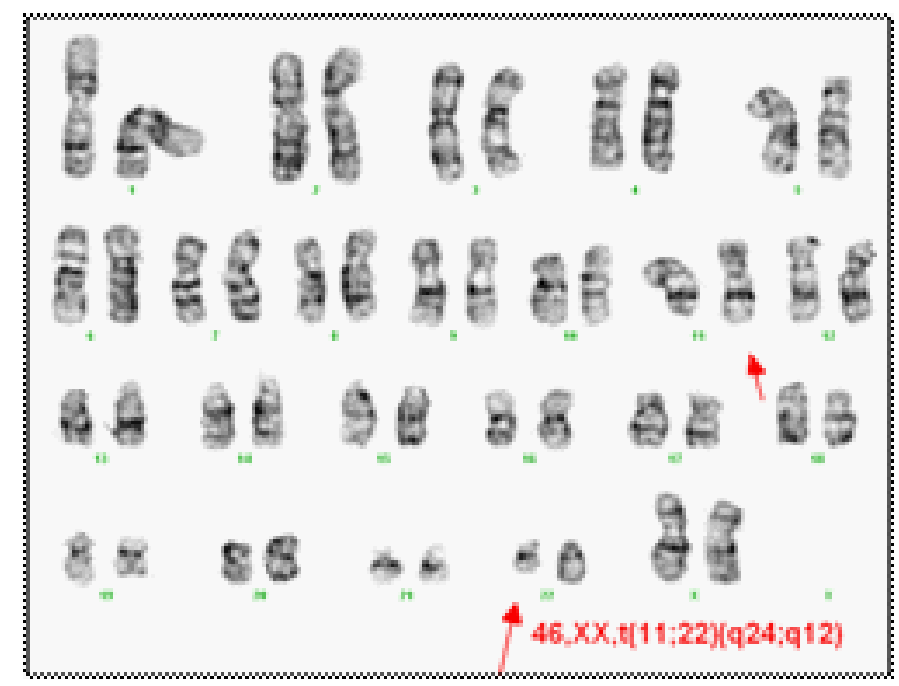

Şek. 1. Ewing Sarkoma'da t(11;22)(q24;q12) 
ların FISH (Floresan İn Situ Hibridizasyon) analizleri de ES ile uyumluydu (Şek. 1).

Başvuru anında 3 olguda ( \%11,1 ) kemik iliği tutulumu saptand1. Toplam 9 olguda $(\% 33,3)$ tanı sirasinda uzak yayılım saptand1. Olguların $\% 69,5$ 'inde takip sirasinda metastaz $(\mathrm{n}=16)$ saptand. Metastaz yerlerine göre; $\% 12,5$ 'inde $(\mathrm{n}=2)$ sadece akciğer, \%6,2'sinde $(\mathrm{n}=1)$ sadece diğer kemik, \%6,2'sinde $(\mathrm{n}=1)$ sadece kemik iliği, $\% 31,3$ 'ünde $(\mathrm{n}=5)$ akciğer ve diğer kemik, \%18,7'sinde $(n=3)$ akciğer, diğer kemik ve kemik iliği, \%6,2'sinde $(n=1)$ akciğer, diğer kemik ve beyin, \%6,2'sinde $(n=1)$ diğer kemik, kemik iliği ve beyin, \%6,2'sinde $(\mathrm{n}=1)$ akciğer, karaciğer, diğer kemik ve kemik iliği, \%6,2'sinde $(n=1)$ akciğer, diğer kemik, kemik iliği, beyin ve orbita metastazı olduğu saptandı.

Tablo 3. Olguların primer kemikte yerleştiği bölgeye göre dağılımı

\begin{tabular}{|l|c|c|}
\hline Primer kemikte yerleştiği bölge & Sayı (n) & Yüzde (\%) \\
\hline Diafiz & 10 & 62,5 \\
\hline Metafizodiafizer & 5 & 31,3 \\
\hline Metafiz & 1 & 6,2 \\
\hline Epifiz & 0 & 0 \\
\hline
\end{tabular}

23 hastaya (\%92) neoadjuvan kemoterapi, 17 hastaya $(\% 77,2)$ adjuvan kemoterapi verildi. Neoadjuvan kemoterapi verilen 23 olgunun 15 'inde $(\% 65,2)$, adjuvan kemoterapi verilen 17 olgunun 9'unda (\%53) Vinkristin, İfosfamid, Doksorubisin, Etoposid (VIDE), Vincristin, Aktinomidin-D, İfosfamid (VAI) ve Vinkristin, Aktinomisin-D, Siklofosfamid(VAC) kemoterapi gruplarından oluşan EURO-E.W.I.N.G. 99 (European Ewing Tumor Working Initiative of National Groups) Kemoterapi Protokolü uygulandi. Neoadjuvan kemoterapi verilen olguların 8'inde $(\% 34,8)$, adjuvan kemoterapi verilen olguların 4'ünde $(\% 23,5)$ Vinkristin, Adriamisin (Doksorubisin), Siklofosfamid, Aktinomisin-D (VACA), Vinkristin, Adriamisin, İfosfamid, Aktinomisin-D (VAIA) ve Etoposid içeren EVAIA kemoterapi guplarından oluşan EICESS-92 (European Intergroup Cooperative Ewing Sarcoma Studies) Kemoterapi Protokolü uygulandığı saptandı. Diğer olgularda da İfosfamid, Etoposid, Karboplatin, Vincristin, Epirubisin, Siklofosfamid kemoterapotik ajanlarından oluşan diğer kemoterapi protokolleri uygulandığı saptandı.

Olguların \%86,6' sına ekstremite koruyucu cerrahi $(\mathrm{n}=13), \% 13,3$ ' üne amputasyon $(\mathrm{n}=2)$ yapıldığ saptandı. 17 olguya $(\% 65,3)$ radyoterapi uygulandi. Radyoterapinin olguların \%64,7'sinde primer tümör bölgesine $(n=11)$, $\% 29,4$ ' ünde metastaz bölgesine $(n=5), \% 5,9$ 'unda hem primer tümör bölgesine hem metastaz bölgesine $(\mathrm{n}=1)$ uygulandığı saptandı.

Olguların sekizinde geç yan etkiler mevcuttu (\% $34,7)$. Dört olguda renal fonksiyonlarda bozukluk, 2 olguda kardiyotoksisite etkiler, 1 olguda işitme kaybı, 1 olguda hem işitme kaybı hem renal yan etkiler geliştiği saptandı.

Olguların son durumları incelendiğinde $\% 48,1$ inin ölüm nedeniyle kaybedildiği ( $\mathrm{n}=13), \% 26$ 'sının hastalıklı hayatta ve tedavisine ettiği $(\mathrm{n}=7), \% 14,8$ ' inin takipten çıktığ $(n=4), \%$ 11,1'inin hastalıksız hayatta oldu- $\breve{g u}(\mathrm{n}=3)$ saptand1. On olgunun hastalık, 1 olgunun sepsis, 2 olgunun hem hastalık hem sepsis sonucu eksitus olduğu saptandi. Tanı anından itibaren olguların ortalama ve ortanca izlem süreleri sirasiyla 35,5 ve 19 ay (en fazla 355 ay) idi. Sağ kalım analizleri sonucunda toplam sağ kalım oran1 \%22,4 $\pm 10,9$ olarak saptand1 (Şek. 2).

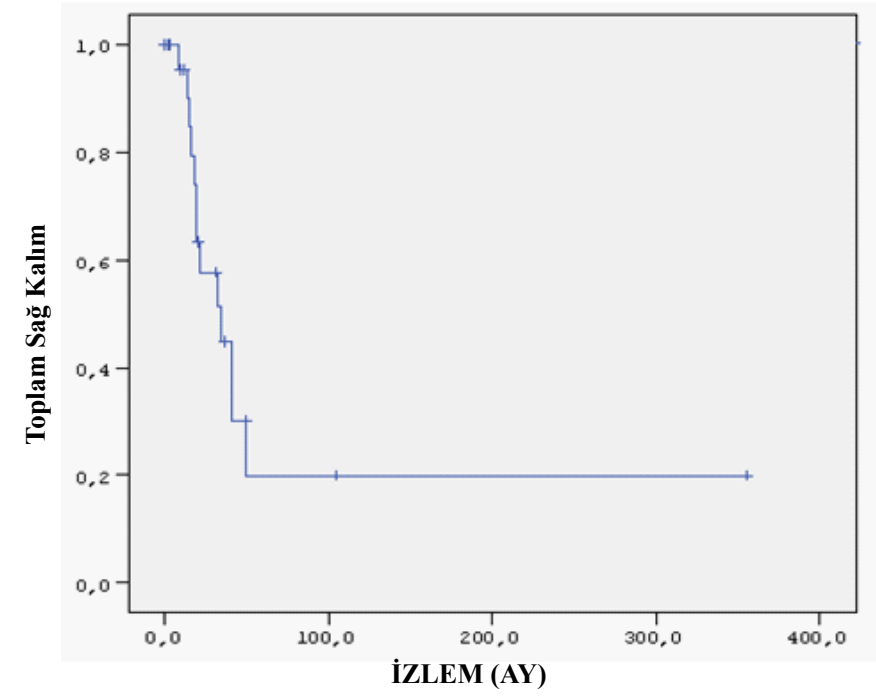

Şek. 2. Ewing Sarkomlu olguların toplam sağ kalım çizelgesi

\section{Tartışma}

Ewing sarkom, osteosarkomdan sonra kemiğin ikinci en s1k malign tümörüdür. Olguların \%80'i 20 yaşın altında olup, insidans1 10-15 yaşlarında pik yapar. Erkeklerde kızlara oranla daha s1k görülmektedir (Redner, 2005; Bernstein ve ark., 2006).

ES olgularımızın ortalama tanı yaşı $11,36 \pm 3,98$ yaş (en küçük yaş 8 ay ve en büyük yaş 17,9) saptandı. Cinsi-

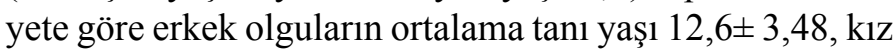
olguların ortalama tanı yaşı 9,05 $\pm 3,96$ saptandı. Ortalama tanı yaşı ülkemizden Sarı ve arkadaşlarının çalışmasında 12 $\pm 3,6$ yıl (3-18 yaş), Kutluk ve arkadaşlarının çalışmasında 10 (1-17 yaş), Özkan ve arkadaşlarının çalışmasında 9 (3-15 yaş), yurt dışından Wagner ve arkadaşlarının çalışmasında 13,4 (4-18 yaş) olarak bulunmuştur (Wagner ve ark., 2001; Kutluk ve ark., 2004; Özkan ve ark., 2005; Sarı ve ark., 2010). Ülkemizde yayınlanan diğer çalışmalarda da ortalama tanı yaşı 9-14 arasında değişmektedir (Ağaoğlu ve ark., 2010; Güler ve ark., 2010; Kantar ve ark., 2010; Sevinir ve ark., 2010). Bizim merkezimizin sonuçları Türkiye'deki diğer merkezlerin sonuçları ve yurt dışındaki literatür ile benzerlik göstermektedir.

Olgularımızın 17'i erkek (\%62,97), 10’u kız $(\% 37,03)$ olup, erkek/k1z oran1 1,7 olduğu saptand1. Erkek/kız oranının Sarı ve arkadaşlarının çalışmasında 1,4, Özkan ve arkadaşlarının çalışmasında 1,7 ve ülkemizdeki diğer merkezlerde yapılan çalışmalarda da 1-1,7 arasında olduğu saptandı (Kutluk ve ark., 2004; Özkan ve ark., 2005; Ağaoğlu ve ark., 2010; Güler ve ark., 2010; Kantar ve ark., 2010; Sar1 ve ark., 2010; Sevinir ve ark., 2010). Paulussen ve arkadaşlarının yaptığı çalışmada erkek/kız oranı 1,5 olarak saptanmıştır (Paulussen ve ark., 2001). Bizim merkezimizin sonuçları Türkiye'deki diğer merkez- 
lerin sonuçları ve yurt dışındaki literatür ile uyumlu bulunmuştur.

En sık görülen yakınmalar diğer malign kemik tümörlerinde olduğu gibi lokal ağrı (\%96) ve şişliktir (\%61) (Redner, 2005; Bernstein ve ark., 2006). Olgularımızda en sık başvuru yakınmalarının lokalize ağrı (\%96.3) ve şişlik (\%100) olduğu tespit edildi (Tablo 1). Başvuru sırasında sistemik yakınmalar arasında iştahsızlık \%40,7 ( $\mathrm{n}=11)$, kilo kayb1 \%25,9 $(\mathrm{n}=7)$, ateş \% 11,1 $(\mathrm{n}=3)$, göğüs ağrısı $\% 7,4(\mathrm{n}=2)$ oranında görüldü. Sarı ve arkadaşlarının çalışmasında olguların \%70'inin şişlik ve ağrı ile başvurduğu, ekstremite lezyonu olan olgularda \%3 oranında patolojik fraktür ve vertebral tutulumu olan olgularda $\% 5$ oranında nörolojik semptomlar görüldüğü saptanmıştır (Sar1 ve ark., 2010). Kutluk ve arkadaşlarının çalışmasında başvuru anında olguların \%74'ünde ağrı, \%72'inde kitle, \%9'unda hiperemi, 1sı artış1 gibi lokal bulgular, \%6'sında parapleji, \%7'sinde öksürük, göğüs ağrısı, idrar inkontinansı veya retansiyonu gibi diğer semptomlar ve \%26'sında ateş, kilo kaybı gibi konsitusyonel semptom ve bulgular saptanmıştır (Kutluk ve ark., 2004). Sevinir ve arkadaşlarının çalışmasında başvuru anında olguların \%84'ünde ağrı, \%51'inde kitle, \%16'sında kilo kaybı, \%13'ünde ateş yakınması saptanmıştır (Sevinir ve ark., 2010). Bu sonuçlar bizim serimiz ile uyumlu bulunmuştur.

Olgularımızı şikâyetlerin başlangıç süresine bakıldığında; tüm olgularda ortalama yakınma süresi $4 \pm 1,03$ aydı. Ortalama yakınma süresi erkeklerde $(n=17)$ $3,94 \pm 0,89$ ay, kızlarda $(\mathrm{n}=10) 4,10 \pm 1,28$ ay saptand1. Olguların \%40,7'sinin $(n=11)$ 1-3 ay arasinda sürelerde yakınması olduğu görüldü. Ortalama yakınma süresi ülkemizden Sarı ve arkadaşlarının çalışmasında olguların \%43'ünde 0-3 ay, \%57'sinde > 3 ay, Kutluk ve arkadaşlarının çalışmasında 3 ay, yurt dışından Widhe ve arkadaşları

Tablo 4. Ewing sarkom olgularında ekstremite ve aksiyel iskelet yerleşim oranları

\begin{tabular}{|l|c|c|c|c|}
\hline Merkez & Sayı (n) & Takip aralığ1 & Ekstremite(\%) & Aksiyel(\%) \\
\hline OMU TF & 27 & $1980-2010$ & 59.3 & 40.7 \\
\hline $\begin{array}{c}\text { Sarı ve ark. } \\
\text { (Ankara } \\
\text { Onk. Hst.) }\end{array}$ & 98 & $1992-2005$ & 59 & 40 \\
\hline $\begin{array}{c}\text { Kutluk ve } \\
\text { ark. } \\
\text { (Hacettepe } \\
\text { Üniv.) }\end{array}$ & 133 & $1972-1999$ & 52 & 46.5 \\
\hline $\begin{array}{c}\text { Özkan ve } \\
\text { ark. } \\
\text { (Cerrahpa- } \\
\text { şa Üniv.) }\end{array}$ & 25 & $1983-2003$ & 76 & 24 \\
\hline $\begin{array}{c}\text { Sevinir ve } \\
\text { ark. } \\
\text { (Uludağ } \\
\text { Üniv.) }\end{array}$ & 31 & $1996-2009$ & 48.4 & 51.6 \\
\hline $\begin{array}{c}\text { Kantar ve } \\
\text { ark. } \\
\text { (Ege Üniv.) }\end{array}$ & 39 & $1990-2008$ & 53.8 & 56.2 \\
\hline $\begin{array}{c}\text { Güler ve } \\
\text { ark. } \\
\text { (Gaziantep } \\
\text { Üniv.) }\end{array}$ & 16 & $2001-2009$ & 68.7 & 50 \\
\hline EICESS & 1426 & & & \\
\hline
\end{tabular}

tarafından 3 ay olarak saptanmıştır (Kutluk ve ark., 2004; Widhe, 2000; Sarı ve ark., 2010). Bu sonuçlar bizim çalışmamızla ile uyumlu bulunmuştur.

Yassı kemikler en sık tutulum bölgesidir. Uzun kemiklerde tipik olarak diafiz bölgesi tutulmaktadır. En sık tutulan yerler sirasiyla pelvik kemikler, alt ekstremitenin uzun kemikleri ve gögüs duvarının kemikleridir. Alt ekstremitede en s1k femur tutulumu görülür (Bernstein ve ark., 2006).

Olgularımızda primer lezyon yeri $\% 59,3(\mathrm{n}=16)$ ekstremitelerde, \%40,7 (n=11) aksiyel iskelette saptand1. Ülkemiz ve yurt dışında yapılan çalışmalarda primer lezyonun ekstremite yerleşimi \%48,4-76, aksiyel iskelet yerleşimi \%24-51,6 arasında değişmektedir (Kutluk ve ark., 2004; Özkan ve ark., 2005; Bernstein ve ark., 2006; Güler ve ark., 2010; Kantar ve ark., 2010; Sar1 ve ark., 2010; Sevinir ve ark., 2010) (Tablo 4). Özkan ve arkadaşlarının çalışması dışındaki sonuçlar bizim çalışmamız ile uyumluydu, aksiyel iskelet tutulumu oranları benzerdi.

Ülkemizde ve yurt dışında yapılan çalışmalarda primer tümörün yerleşim oranları femur için \%12,9-26, pelvis için \%13,5-32,3 arasında değişmektedir (Kutluk ve ark., 2004; Bernstein ve ark., 2006; Güler ve ark., 2010; Sevinir ve ark., 2010)(Tablo 5). Bizim çalışmamızın sonuçları Kutluk ve arkadaşlarının sonuçlarıyla uyumluydu ve kitlenin en s1k primer yerleşim yeri femurdu (Tablo 2). Ayrıca olgularımızda en sık olarak diafiz $(\% 62,5)$ ve metafizodiafiz (\%31.3) tutulumu mevcuttu (Tablo 3).

Olguların başvuru sırasındaki ortalama tümör volümü erkeklerde 1304,69 $\pm 1606 \mathrm{ml}$, kızlarda $2331,05 \pm 1962$ ml idi. Tümör volümü bilinen 20 olgunun $\% 90$ '1nda ( $\mathrm{n}=18)$ $\geq 100 \mathrm{ml}, \% 10$ 'unda $(\mathrm{n}=2)<100 \mathrm{ml}$ saptand. 1981-1985 yılları arasında 60 ES'lu olgunun değerlendirildiği Göbel ve arkadaşlarının çalışmasında tümör volümü 33 olguda $(\% 55)<100 \mathrm{ml}, 27$ olguda $(\% 45) \geq 100 \mathrm{ml}$ olarak tespit edilmiş ve 3 yıllık hastalıksız sağ kalım oranları tümör volümü $<100 \mathrm{ml} \% 78$ ve $\geq 100 \mathrm{ml}$ olanlarda $\% 17$ olarak saptanmıştır (Göbel ve ark., 1987). Sarı ve arkadaşlarının çalışmasında tümör volümü olguların $\% 28$ 'inde $\leq 8 \mathrm{~cm}$ ve $\% 67$ 'sinde $>8 \mathrm{~cm}$; Kutluk ve arkadaşlarının çalışmasında olguların \%83'ünde tümör boyutu $\geq 8 \mathrm{~cm}$ olarak bulunmuştur (Kutluk ve ark., 2004; Sarı ve ark., 2010). Hem bizim çalışmamızda hem de Türkiye'deki bildirilen diğer verilerde tümör volümü Göbel ve arkadaşlarının çalışmasına göre daha yüksek bulunmuştur; bu ülkemizde hastaneye daha geç başvurulması nedeniyle olduğunu düşünmekteyiz.

Tablo 5. Ewing sarkom olgularında primer lezyonun yerleştiği kemikler

\begin{tabular}{|l|c|c|c|}
\hline Merkez & Sayı (n) & Takip aralığı & Primer yerleştiği kemik (\%) \\
\hline OMU TF & 27 & $1980-2010$ & Femur (26), Tibia(14.8), Pelvis (14.8) \\
\hline $\begin{array}{l}\text { Kutluk ve ark. } \\
\text { (Hacettepe } \\
\text { Üniv.) }\end{array}$ & 133 & $1972-1999$ & Femur (23), Tibia(14), Pelvis (13.5) \\
\hline $\begin{array}{l}\text { Sevinir ve ark. } \\
\text { (Uludağ Üniv.) }\end{array}$ & 31 & $1996-2009$ & Pelvis (32.3), Femur (12.9) \\
\hline $\begin{array}{l}\text { Güler ve ark. } \\
\text { (Gaziantep } \\
\text { Üniv.) }\end{array}$ & 16 & $2001-2009$ & Humerus (43.7), Pelvis(25), Femur (18.7) \\
\hline EICESS & 1426 & - & Pelvis(26), Femur (20), Göğüs duvarı (16) \\
\hline
\end{tabular}


Olgularımızın \% 77,8' inde tanının insizyonel biyopsi ile $(n=21), \% 14,8$ 'ine eksizyonel biyopsi $(n=4)$, $\% 7,4$ 'üne tru-cut biyopsi $(\mathrm{n}=2)$ ile tan 1 konulduğu saptandı. Sarı ve arkadaşlarının çalışmasında olguların \%76'sında insizyonel, \%20'sinde eksizyonel ,\%4'ünde tru-cut biyopsi yapılmıştır (Sarı ve ark., 2010). Bazı merkezlerde iğne biyopsisi veya tru-cut biyopsi önerilirse de hastaların çoğu uygun ve tümörlü dokuyu içerecek şekilde açık biyopsi yapılmasını gerektirir (Yağc1 ve Kutluk, 2009) Çünkü açı insizyonel biyopsi histopatolojik inceleme için yeterli materyal alınabilmesinin yanısıra sitogenetik ve diğer biyolojik araştırmalar için de örnek alınmasına izin veren bir yöntemdir (Kısmet ve Köseoğlu, 2004).

Tanı anında hastaların yaklaşı \%20-30'unda metastaz vardır ve metastatik hastalığın varlığı en önemli kötü prognostik faktördür (Cotterill ve ark., 2000; Redner, 2005; Bernstein ve ark., 2006). Metastatik olmayan hastalarda hemen hemen tüm tedavi protokolleriyle benzer şekilde iyi sonuçlar elde edilirken, metastatik grupta her hastada farklı cevap oranları gözlenmektedir (RodríguezGalindo ve ark., 2007).

Başvuru anında 3 olgumuzda $(\% 11,1)$ kemik iliğ i tutulumu saptand1. Toplam 9 olguda $(\% 33,3)$ tanı sirasinda metastaz saptand. Olgularımızın $\% 69,5$ ' inde takip sirasinda metastaz $(\mathrm{n}=16)$ saptandı. Ülkemizde ve yurt dışında yapılan çalışmalarda tanı anında metastaz oranları \%18,450 oranında değişmektedir (Cotterill ve ark., 2000; Kutluk ve ark., 2004; Özkan ve ark., 2005; Güler ve ark., 2010; Sevinir ve ark., 2010) (Tablo 6). Batı ülkelerindeki çoğu çalışmada tanı anındaki metastaz oranı $\% 25$ ve altında bulunmuştur (Cotterill ve ark., 2000; Bernstein ve ark., 2006). Bizim çalıșmamızın sonuçları Türkiye'deki diğer merkezlerin sonuçları ile benzerdir, yurt dışındaki verilere göre daha yüksek oranda tanı anında metastaz oranlarımız mevcuttu. Bizim serilerimizde hastalarımız geç dönemde başvurduklarından, sosyoekonomik düzeyleri düşük olduğundan tanı anında metastaz oranlarımız daha fazlaydı. Ayrıca 2002 yılına kadar hastaların sağlık güvenceleri pek uygun olmadığından takip ve tedavideki başarı oranları düşüktü.

Olgularımızdan 23 hastaya (\%92) neoadjuvan kemoterapi, 17 hastaya $(\% 77,2)$ adjuvan kemoterapi verildi. Neoadjuvan kemoterapi verilen 23 olgunun 15 'inde (\%65,2), adjuvan kemoterapi verilen 17 olgunun 9'unda (\%53) EURO-E.W.I.N.G. 99 (European Ewing Tumor Working Initiative of National Groups) Kemoterapi Protokolü uygulandi. Neoadjuvan kemoterapi verilen olguların 8 'inde $(\% 34,8)$, adjuvan kemoterapi verilen olguların 4'ünde $(\% 23,5)$ EICESS-92 (European Intergroup Cooperative Ewing Sarcoma Studies) Kemoterapi Protokolü

Tablo 6. Ewing sarkom olgularında tanı anındaki metastaz oranları

\begin{tabular}{|l|c|c|c|}
\hline Merkez & Sayı (n) & Takip aralığı & Tanı anında metastaz (\%) \\
\hline OMU TF & 27 & $1980-2010$ & 33,3 \\
\hline Kutluk ve ark. & 133 & $1972-1999$ & 32 \\
\hline Özkan ve ark. & 25 & $1983-2003$ & 36 \\
\hline Sevinir ve ark. & 31 & $1996-2009$ & 45,2 \\
\hline Güler ve ark. & 16 & $2001-2009$ & 50 \\
\hline Cotteril ve ark. & 975 & $1977-1993$ & 18,4 \\
\hline
\end{tabular}

Tablo 7. Ewing sarkom olgularında toplam sağ kalım oranları

\begin{tabular}{|c|c|c|c|c|}
\hline Merkez & Sayı (n) & Takip aralığ1 & Ort. izlem süresi & Toplam sağ kalım \\
\hline OMU TF & 27 & $1980-2010$ & 35.5 (enfazla355ay) & $\begin{array}{c}\% 22,4 \pm 10,9 \\
\text { Genel sağkalım }\end{array}$ \\
\hline $\begin{array}{c}\text { Sarı ve ark. } \\
\text { (Ankara } \\
\text { Onk. Hst.) }\end{array}$ & 98 & $1992-2005$ & $\begin{array}{c}105 \pm 38 \text { ay } \\
(47-178 \text { ay) }\end{array}$ & $\begin{array}{c}\% 47 \\
5 \text { yıllık }\end{array}$ \\
\hline $\begin{array}{c}\text { Kutluk ve } \\
\text { ark. } \\
\text { (Hacettepe } \\
\text { Üniv.) }\end{array}$ & 133 & $1972-1999$ & $\begin{array}{c}84.5 \text { ay } \\
(25-332 \text { ay) }\end{array}$ & $\begin{array}{c}\% 31 \\
10 \text { yıllık }\end{array}$ \\
\hline $\begin{array}{c}\text { Özkan ve } \\
\text { ark. } \\
\text { (Cerrahpasa } \\
\text { Unniv.) }\end{array}$ & 25 & $1983-2003$ & $\begin{array}{c}50 \text { ay } \\
(4-108 \text { ay) }\end{array}$ & $\begin{array}{c}\% 31,1 \\
4 \text { y1llk }\end{array}$ \\
\hline $\begin{array}{c}\text { Güler ve } \\
\text { ark. } \\
\text { (Gaziantep } \\
\text { Üniv.) }\end{array}$ & 16 & $2001-2009$ & $26 \pm 23,5$ ay & $\begin{array}{c}\% 40,4 \\
\text { y1llık }\end{array}$ \\
\hline $\begin{array}{c}\text { Paulussen } \\
\text { ve ark. }\end{array}$ & 171 & $1990-1995$ & 41 ay(14-82 ay) & $\begin{array}{c}27 \\
4 \text { yıllık }\end{array}$ \\
\hline
\end{tabular}

uygulandığı saptandı. Diğer olgularda da İfosfamid, Etoposid, Karboplatin, Vincristin, Epirubisin, Siklofosfamid kemoterapotik ajanlarından oluşan diğer kemoterapi protokolleri uygulandığı saptandı. 98 hastanın değerlendirildiği Sarı ve arkadaşlarının çalışmasında hastaların tamamının EICESS-92 (European Intergroup Cooperative Ewing Sarcoma Studies) Kemoterapi Protokolü ile tedavi edildiği, Kantar ve arkadaşlarının çalıșmasında olguların \%48.7'sinde EICESS-92 kullanıldığ1 saptanmıştır (Kantar ve ark., 2010; Sarı ve ark., 2010).

Olgularımızın \%86,6' sina ekstremite koruyucu cerrahi (n=13), \%13,3' üne amputasyon $(n=2)$ yapıldığg 1 saptandı. Kutluk ve arkadaşlarının çalışmasında ilk tanı anında olguların \%2'sine amputasyon, \% $\% 3$ 'üne insizyonel biyopsi, \%9'una total rezeksiyon, \%9'una parsiyel rezeksiyon ve \%7'sine subtotal rezeksiyon yapılmıştır (Kutluk ve ark., 2004).

Olgularımızın \%65,3'üne $(\mathrm{n}=17)$ radyoterapi uyguland. Radyoterapinin olguların \%64,7'sinde primer tümör bölgesine ( $\mathrm{n}=11), \%$ 29,4' ünde metastaz bölgesine $(\mathrm{n}=5), \% 5,9$ ' unda hem primer tümör bölgesine hem metastaz bölgesine $(\mathrm{n}=1)$ uygulandığ 1 saptand1. Sar1 ve arkadaşlarının çalışmasında radyoterapi olguların \%80'ine uygulanmış ve \%70'inde primer tümör bölgesine ,\%1'inde metastarik bölgeye ,\%9'unda her ikisine uygulanmış (Sarı ve ark., 2010). 133 olgunun değerlendirildiği Kutluk ve arkadaşlarının çalışmasında 121 olguya (\%91) radyoterapi uygulanmış ve 113 olguda primer tümör bölgesine, 2 olguda metastatik bölgeye, 6 olguda hem metastatik hem primer tümör bölgesine uygulanmıştır (Kutluk ve ark., 2004). 16 olgunun değerlendirildiği Güler ve arkadaşların çalışmasında radyoterapi 12 olguda primer tümör bölgesine, 2 olguda primer tümör bölgesi ve akciğere uygulanmıştır (Güler ve ark., 2010). Bu sonuçlar bizim serimiz ile uyumlu bulunmuştur.

Çalışmamızda olgularımızın tanı anından itibaren ortalama ve ortanca izlem süreleri sirasıyla 35,5 ve 19 ay (en fazla 355 ay) idi. Sağ kalım analizleri sonucunda toplam sağ kalım oranı $\% 22,4 \pm 10,9$ olarak saptandı. Ülkemizde yurt dışından yapılan yayınlarda sağ kalım oranları \%27-47 arasında değișmektedir (Paulussen ve ark., 1998; 
Kutluk ve ark., 2004; Özkan ve ark., 2005; Güler ve ark., 2010; Sar1 ve ark., 2010) (Tablo 7).

Ewing sarkomunda tedavi başarısızlığının major sebebi uzak metastaz gelişmesidir (Bürgert ve ark., 1990; Nesbit ve ark., 1990). Yapılan çoğu çalışmada Ewing sarkomda metastatik hastalık varlığında toplam sağkalım oranları \%20-30 olarak bildirilmiştir (Sandoval ve ark., 1996; Paulussen ve ark., 1998). Bizim çalışmamızda sağ

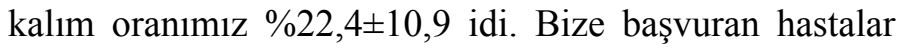
geç evrede gelmekteydi ve sosyo ekonomik ve sosyokültürel düzeyi düşük ailelerdi ve tanı anında metastazımız yüksekti. Ayrıca bizim serimiz 30 yıl öncesine dayanmaktaydı ve gerek kemoterapi gerekse modern cerrahi tedavi imkanlarının az olduğu dönemleri kapsıyordu.

Son on yılda lokalize Ewing sarkomlu olgularda sağ kalım oranları anlamlı şekilde \%20'den \%50'ye artmiştır (Bacci ve ark., 1998; Jenkin ve ark., 2002). Gelişmekte olan ülkelerde geç tanı hala önemli bir problemdir ve hastalık çoğu hastada ilerlemiş durumdadır (Villarroel ve ark., 1997; Cardenas-Cardos ve ark., 1999; Jenkin ve ark., 2002). Ewing sarkomunda tedavi başarısı için erken tanıdan rehabilitasyona kadar her aşamada multidisipliner bir yaklaşım gerekmektedir. Gelişmekte olan ülkelerde eksiklikler hastanın yaşam şansını ve yaşam kalitesini doğrudan etkilemekledir.

\section{KAYNAKLAR}

Ağaoğlu, F.Y., Kebudi, R., Almaç, Z., 2010. Pediatrik Ewing Sarkomalarda Lokal Tedavi:İstanbul Üniversitesi Onkoloji Enstitüsü Deneyimi. XVI.TPOG Ulusal Pediatrik Kanser Kongresi, Samsun. Kongre Kitabı. 119.

Bacci, G., Picci, P., Ferrari, S., 1998. Neoadjuvant chemotherapy for Ewing's sarcoma of bone: no benefit observed after adding ifosfamide and etoposide to vincristine, actinomycin, cyclophosphamide, and doxorubicin in the maintenance phase-results of two sequential studies. Cancer. 82, 1174-1183.

Bernstein, M., Kovar, H., Paulussen, M., Randall, R.L., 2006. Ewing's Sarcoma Family of Tumors: Ewing sarcoma of bone and soft tissue and the peripheral primitive neuroectodermal tumors. "Principles and Practice of Pediatric Onco-logy”(Ed.PA Pizzo, DG Poplack)'de, 5.baski, Lippincott Williams \& Wilkins Philadelphia.1002-1032.

Bürgert, E.O., Nesbit, M.E., Ganisey, L.A., 1990. Multimodal therapy for the management of nonpelvie. localized Ewing's sarcoma of bone: Intergroup study ffiSS-H. J. Clin. Oncol. 8, 1514-1524.

Cardenas-Cardos, R., Rivera-Luna, R., Lopez-Facundo, N.A., 1999. Ewing's sarcoma: prognosis and survival in Mexican children from a single institution. Pediatr. Hematol. Oncol. 16, 519-523.

Cotterill, S.J., Ahrens, S., Paulussen, M., 2000. Prognostic factors in Ewing's tumor of bone: analysis of 975 patients from the European Intergroup Cooperative Ewing's Sarcoma Study Group. J. Clin. Oncol. 18, 3108-3114.

Ewing, J., 1921. Diffuse endothelioma of bone. Proc. NY Pathol. Soc. 21, 17-24.

Fizazi, K., Dohollou, N., Blay, J.Y., 1998. Ewing's family of tumors in adults: multivariate analysis of survival and longterm results of multimodality therapy in 182 patients. J. Clin. Oncol.16, 3736-3743.

Göbel, V., Jürgens, H., Etspüler, G., 1987. Prognostic significance of tumor volume in localized Ewing's sarcoma of bone in children and adolescents. J. Cancer Oncol. 113, 187-191.

Güler, E., Çevik, S., Karakurum, G., 2010. Ewing Sarkom Olgularımızın Değerlendirilmesi:Gaziantep Tıp Fakültesi Deneyimi. XVI.TPOG Ulusal Pediatrik Kanser Kongresi,Samsun. Kongre Kitab1 143.

Jenkin, R.D., Al-Fawaz, I., Al-Shabanah, M.O., 2002. Localized Ewing sarcoma/PNET of bone: prognostic factors and international data comparison. Med. Pediatr. Oncol. 39, 586-593.

Jürgens, H., Barrett, A., Dockhorn-Dworniczak, B., Winkelmann, 1998. Ewing sarcoma, in Cancer in Children: Clinical Management, Voute PA, Kalifa C and Barrett A, eds, 4th ed, Oxford Med. Publicat. 232-258.

Kantar, M., Keleş, Y.E., Arun, S., 2010. Ewing Ailesi Tümörleri Tedavi Sonuçları:Ege Üniversitesi Deneyimi. XVI. TPOG Ulusal Pediatrik Kanser Kongresi, Samsun, Kongre Kitab1 142-143.

Kennedy, J.G., Fielinghuysen, P., Hoang, B.H., 2003. Ewing sarcoma: curren; concepts in diagnosis and treatment, Curr. Opin. Pediatr. 1553-1557.

Khoury, J.D., 2005. Ewing sarcoma family of tumors. Adv. Anat. Pathol. 12, 212-220.

Kismet E,Köseoğlu V, 2004.Turkiye Klinikleri J. Pediatr. Sp. Iss. 2, 899-903.

Kutluk, M.T., Yalcin, B., Akyüz, C., 2004. Treatment results and prognostic factors in Ewing Sarcoma. Pediatr. Hematol. Oncol. 21, 597-610.

Kutluk, T.,Yeşilipek, A., 2010.Türk Pediatrik Onkoloji Grubu/Türk Pediatrik Hematoloji Derneği Pediatrik Tümör Kay1tları,2002-2009 Ulusal Pediatrik Kanser Kongresi, Samsun.

Nesbit, M.E., Gehan, E.A., Burgen, E.O., 1990. Multimodal therapy for the management of primary, nonmetastatic Ewing's sarcoma of bone: A long-term follow-up of the First Intergroup study. J. Clin. Oncol. 8,1664-1674.

Özkan A, Celkan T, Apak H, et al., 2005. Cerrahpaşa Tıp Fakültesi Ewing Sarkom Deneyimi:1983-2003. Ewing sarcoma: results of a single institute from Turkey,1983-2003.Türk Pediatri Arşivi. 40, 232-234.

Paulussen, M., Ahrens, S., Burdach, S., 1998. Primary metastatic (stage IV) Ewing tumor: survival analysisof 171 patients from the EICESS studies. European Intergroup Cooperative Ewing Sarcoma Studies. Ann Oncol. 9, 275-281.

Paulussen, M., Ahrens, S., Dunst, J., 2001.Localized Ewing Tumor of Bone:Final Results of the Cooperative Ewing's Sarcoma Study CESS 86. J. Clin. Oncol.19, 1818-1829. 
Redner, A., 2005. Malignant bone tumors. Pediatric Hematology and Oncology, Lanzkowsky P, ed, 4rd ed. California: Academic Press. 585-603.

Rodríguez-Galindo, C., Liu, T., Krasin, M.J., 2007. Analysis of prognostic factors in ewing sarcoma family of tumors: review of St. Jude Children's Research Hospital studies. Cancer. 15, 375-384.

Sandoval, C., Meyer, W.H., Parham, D.M., 1996. Outcome in 43 children presenting with metastatic Ewing's sarcoma: the St. Jude Children's Research Hospital experience, 1962 to 1992. Med. Pediatr. Oncol. 26, 180-185.

Sarı, N., Toğral, G., Çetindağ, M.F., 2010. Treatment Result Of the Ewing Sarcoma of Bone and Prognostic Factors. Pediatric Blood Cancer. 54, 19-24.

Sevinir, B., Demirkaya, M., Yalçınkaya, Ü., 2010. Ewing Sarkomunda Klinik Özellikler ve Tedavi Sonuçları. XVI. TPOG Ulusal Pediatrik Kanser Kongresi, Samsun, Kongre Kitab1 141.

Villarroel, M., Tordecilla, J., Salgado, C., 1997. Multimodal therapy for children and adolescents with Ewing sarcoma: results of the First National Chilean Trial (1986-1991). Med. Pediatr. Oncol. 29, 190-196.

Wagner, L.V., Neel, M.D., Pappo, A.S., 2001. Fractures in pediatric Ewing sarcoma. J. Pediatr. Hematol. Oncol. 23, 568-571.

Widhe, B.,Widhe, T., 2000. Initial symptoms and clinical features in osteosarcoma and Ewing sarcoma. J. Bone Joint Surg. Am. 82, 667-674.

Yağcı, B., Kutluk, T., 2009. Ewing sarkom. Pediatr. Onkoloji. 995-1000. 